\title{
A Targeted Material Selection Process for Polymers in the Laser Sintering Process
}

\author{
G.M. Vasquez*, C.E. Majewski**+, B. Haworth*, N. Hopkinson**
}

+ Corresponding author - Email: C.Majewski@sheffield.ac.uk, Tel: +44 (0) 114222

7791

* Department of Materials, Loughborough University, Loughborough, Leicestershire

\section{LE11 3TU, UK}

** Department of Mechanical Engineering, University of Sheffield, Sir Frederick Mappin Building, Mappin Street, Sheffield, S1 3JD, UK,

\begin{abstract}
Laser sintering (LS) of polymer materials is a process that has been developed over the last two decades and has been applied in industries ranging from aerospace to sporting goods. However, one of the current major limitations of the process is the restricted range of usable materials. Various material characteristics have been proposed as being important to optimise the laser sintering process, key aspects of which have been combined in this work to develop an understanding of the most crucial requirements for LS process design and materials selection. Using the favourable characteristics of polyamide-12 (the most often used material for laser sintering) as a benchmark, a previously un-sintered thermoplastic elastomer material was identified as being suitable for the LS process, through a combination of information from Differential Scanning Calorimetry (DSC), Hot Stage Microscopy (HSM) and knowledge of viscosity data. Subsequent laser sintering builds confirmed the viability of this new material, and tensile test results were favourable when compared with materials that are currently commercially available, thereby demonstrating the efficacy of the chosen selection process.
\end{abstract}


Keywords: Laser sintering, materials selection, elastomer, Additive Manufacturing

\section{Introduction}

\section{$1 \quad$ Laser Sintering (LS)}

Laser sintering is an Additive Manufacturing (AM) technology in which a laser is used to construct 3-dimensional parts, layer by layer, from consolidated polymer, ceramic, or metal powder [1]. Major benefits of taking an AM approach stem from the lack of requirement for any form of tooling, allowing the production of highly complex geometries and assemblies, as well as the capability of producing personalised products for little or no extra cost. Whilst AM technologies were initially focussed on the production of prototypes, mainly for product visualisation, in recent years there has been increasing interest in the use of these technologies for the production of end-use parts, in almost all industrial sectors. LS in particular has demonstrated substantial potential in this area, due to the high levels of geometric complexity achievable, and the relatively high mechanical properties and levels of consistency which can be achieved.

In 2012, the AM industry as a whole (including machine sales, materials, servicing \& maintenance and service bureaus) grew $28.6 \%$ from the previous year, to a level of $\$ 2.204$ billion, and is predicted to have reached the $\$ 10$ billion mark by 2021 [2]. Approximately $20 \%$ of the 2012 total (\$422.6 million) was solely for AM materials, of which just under one third of this was for LS polymer materials alone. However, whilst laser sintering of polymers has generated substantial commercial interest, the restricted range of materials available for this technology is a barrier to its more wide-scale adoption and market growth. Part of this technological inertia arises from a lack of understanding of the most relevant physical properties of polymers that underpin their behaviour in the LS process and how the thermomechanical history then 
influences the micro- and macrostructures of components, hence their performance inservice.

\subsection{Industrial Context}

The adoption of Additive Manufacturing, allowing exploitation of its design freedom, has become widespread throughout many industries, but the creation of highly flexible and elastic parts is a target that cannot always be solved when using the most commonly-available powders: polyamide (PA) based laser sintering materials (PA-11 and PA-12). Even though polyamide parts are strong enough and sufficiently durable to be used as functional prototypes, their limited range of mechanical properties constrains engineers and designers. Burton Snowboards, a USA-based snow sports company based in Vermont, USA was one of the industrial collaborators for the research reported here. They currently utilise additive manufacturing techniques to streamline the design process for many of their rigid snowboard binding products shown in Figure 1.

In fact, laser sintered PA-12 parts are robust enough to use as 'on-snow' functional prototypes. However, the product line also includes many components that demand more elastomeric properties, especially at high deformations and in cold weather applications. There are relatively few commercially available elastomer materials currently available for LS processes (examples include: ALM TPE-210s and 3D Systems Duraform Flex), which then makes these powders more expensive compared to standard polyamide powder. Subsequently there has been only a narrow academic focus on elastomer laser sintering materials to-date, especially on understanding the range of physical properties required for optimum sintering within the LS process.

\section{Figure 1}

\subsection{Materials for Laser Sintering}


While ceramic and metal laser sintering is common, the focus of this work will be on polymer laser sintering, to include both rigid and flexible polymer variants. Traditionally the range of materials for LS has been fairly restricted, particularly when considering polymers. For the purposes of this paper polymer sintering is defined as the 'formation of a homogenous melt from the coalescence of powder particles' [3]. As the requirement for end-use products has increased, so too has the demand for a wider variety of polymer materials, covering an increasing range of mechanical properties, and therefore applications. To provide some context, there are currently many thousands of injection moulding grade materials commercially available, whereas for LS there are approximately 30 [4].

Much of the previous research into the development of new materials for LS has used a somewhat 'trial and error' approach, leading to longer development cycles, and in many cases never reaching a satisfactory conclusion. In addition, whilst there is a wealth of published data available suggesting the required raw material characteristics for a successful LS material, it can be difficult to distinguish between those traits which are crucial for good sintering, and those which are simply 'desirable', including end-use criteria. Optimisation procedures for the LS machine process parameters, based upon polymer properties, are also in an early stage of development. Numerous attempts have been made to laser sinter individual materials and some authors have reported their attempts to tailor machine parameters to the specific case. [5] investigated laser scan power, laser scan spacing and bed temperature control in the processing of an experimental elastomer material called Dupont Somos 200. Other research has examined various additional materials in attempts to control their processing including polystyrene [6], polycarbonate [6],[7], UHMWPE [8] and PEEK [9]. This work has been beneficial in identifying some requirements for successful laser sintering but 
specific conclusions on basic polymer sintering characteristics have not been extensively investigated.

The major focus of the research presented here was therefore to build on previous research in this area [10] and to provide insight into the main raw material requirements that must be met in order to develop a successful material for LS. In order to achieve this, the most favourable characteristics of the standard LS material, Polyamide-12, have been selected and applied, in order to identify a new elastomeric material with potential use in LS component applications. The results of this are validated through LS process investigations, both in terms of a qualitative assessment of the ease of sintering, and through the production and testing of standard tensile test specimens produced using LS.

\subsection{Laser Sintering System Design}

Prior to discussing the characteristics required for a new laser sintering material, it is necessary to understand the main characteristics of an LS processing system. There are several different laser sintering systems however they all share a basic design (Figure 2). The build takes place inside a nitrogen controlled atmosphere on a heated platform that indexes down about $0.1-0.15 \mathrm{~mm}$ after each layer is sintered. During a typical PA-12 build the part bed is heated to a point about $12^{\circ} \mathrm{C}$ below the crystalline melting endotherm temperature. This is to prevent steep thermal gradients that would occur when the laser melts the material, which can lead to distortion of sintered parts and build failure. A direct beam $\mathrm{CO}_{2}$ laser applies energy to the material to take it above the endothermic melting range to a point where the material is able to flow under low stress, to facilitate sintering. The un-sintered powder surrounding the part acts as support. This loose material is brushed off the part when it is cleaned following completion of the build cycle. Some of the more important process variables affecting 
the development of sintering include bed temperature, layer thickness, laser power, scan speed and scan spacing; the latter three variables are considered in detail as part of the research investigations (section 4.1.2).

\section{Figure 2}

\section{$1.4 \quad$ Polyamide-12 (PA12)}

Polyamide-12 is a rigid, semi-crystalline thermoplastic material and is by far the most common polymeric material used in LS, accounting for roughly $95 \%$ of the total polymer sintering market [12]. The main reason for this is simply that it possesses particularly favourable thermal characteristics for the process, the key aspects of which are presented in the following sections.

\subsubsection{Melting and Re-crystallization Characteristics}

The use of Differential Scanning Calorimetry (DSC) allows the identification of the melting and re-solidification behaviour of a material, and is a particularly useful tool for the identification, development and optimisation of LS materials. Essential parameters are the phase transformations during melting and cooling / re-solidification. The relatively sharp melting endotherm of PA12 allows the polymer powder to be heated to just below the melting point throughout the build process cycle. This is more difficult for amorphous materials because of the more gradual transition towards the required, predominantly viscous deformation behaviour during sintering, as temperature increases.

The second key thermal characteristic required for effective sintering is the possession of a wide super-cooling range [13], defined as the difference between the temperatures at the onset of melting (in the heating cycle) and re-crystallisation on cooling. Typical DSC traces of an amorphous and semi-crystalline material are shown in Figure 3. The semi-crystalline material has two sharp peaks representing the melting 
endotherm and exothermic recrystallization phases of the material. The area between these two peaks is considered the super-cooling window and for most laser sintering materials it is ideal to set the part bed temperature to a point between these two values. This promotes good control of sintering when the powder absorbs energy from the laser and allows effective part consolidation by avoiding premature crystallisation on cooling. Once the temperature of the powder increases beyond the upper limit of the melting endotherm, sintering progresses within the melt state through viscoelastic deformation under low stress conditions.

In contrast, amorphous materials do not show distinct transitions, so that changes in thermal and flow behaviour are more gradual. This can make laser sintering much more challenging because small percentages of the material may start to flow at lower and more variable temperatures, which could inhibit powder flow across the part bed due to the temperature sensitivity of thermal and viscous characteristics.

\section{Figure 3}

\subsubsection{Beyond the Melting Endotherm}

Many polymers are notoriously sensitive to changes in chemical structure due to excessive thermal and / or mechanical stimuli applied during a process cycle. In conventional processes such as mixing or injection moulding, chain scission often occurs with a corresponding reduction in molecular weight. More complex structural effects may also occur, depending upon the type of chemical reaction mechanism involved, such as crosslinking. In turn, these changes in structure lead to significant differences in some important physical properties relevant to sintering processes, including melt viscosity. In PA12, polycondensation reactions are thought to lead to chain extension and an increase in viscosity [14], thereby compromising the ability to use recycled powders in subsequent builds. An attempt has been made to allow a more 
precise determination of a stable, or optimum sintering region at temperatures above the melting endotherm of polymers used in laser sintering, using a combination of thermal analysis techniques: DSC and thermogravimetric analysis (TGA) [10].

\subsubsection{Sintering Behaviour}

Hot stage microscopy (HSM) has been used to optically observe the consolidation of polymer powder particles, to validate predictive studies of particle sintering (eg. [3], [14]. Hot stage microscopy has been used to evaluate five different laser sintering materials to report the sintering speed of various materials and showed that elastomer materials tend to completely consolidate more slowly than polyamides [10]. The implication of this observation is that full melting and consolidation can be difficult to achieve for elastomers in the processing time scales normally used in laser sintering. In addition, the thermal behaviour of new elastomers must comply, to some extent, with the criteria defined in Section 1.4.1.

The ability to simulate the sintering process is an important requirement for future development of new materials and enhanced process design. The usual starting point is to consider relationships such as those described by Equation 1, which shows the Frenkel-Eshelby viscous model that can be used in predictive mode alongside practical measurement to characterise sintering rates of polymer materials. The model assumes that two spherical particles are able to flow and coalesce as a function of time (Figure 4), with the fundamental driving properties being viscosity and surface free energy. More specifically, viscosity data should be obtained under low stress conditions to reflect the nature of sintering; a zero-shear viscosity parameter is considered appropriate [14]. The model has been verified experimentally using amorphous polymers such as PMMA and polystyrene [3] 
where $y$ is the half neck radius, $a$ is the initial particle radius, $\Gamma$ is surface energy, $\mu$ is viscosity, and $t$ is (sintering) time.

\section{Figure 4}

Equation 1 demonstrates a simple viscous model, with parameter $(\mu)$ chosen to represent the melt viscosity at very low deformation rates. The dependence of sintering behaviour on surface free energy, together with the assumption that particle radius (a) remains constant, implies that the Frenkel-Eshelby model is valid for the early stages of the sintering process. On this basis, for any given polymer type, changes to molar mass (or to additive concentration) are likely to have a profound influence on the zero-shear viscosity parameter, which may vary by orders of magnitude when molecular weight changes significantly. This has important implications for materials selection.

Previous attempts have been made to correlate practical sintering behaviour to HSM observations and research continues to develop more accurate and robust process models for melt-state sintering process, for example to take account of viscoelastic effects. Publications by Bellehumeur et al provide evidence to show that elastic effects are also important in polymer sintering and contribute to reduced sintering rates [3], [15]. In LS processes, the overall thermomechanical effects are very complex since thermal gradients will be present in the powder particles, influencing the physical parameters that are temperature-dependent. In addition, chemical changes may also take place so that overall, accurate properties data are essential, as the refinement of process models is developed further.

\subsubsection{Particle Properties}


It has been suggested that powder flow is a key parameter for selecting new materials for the process [16]. Powder flow can be affected by particle size and is also a key determinant of surface finish. Larger particles are less likely to melt completely due to the poor thermal diffusivity of polymer powders, which may result in porosity (decreased mechanical properties) and rougher surfaces on sintered parts. Surface morphology is also significant, due to its effect on the surface area / volume ratio, an observation that has implications for the techniques by which powders are prepared. The effects of particle size / size distribution and morphology in LS processes are yet to be fully investigated.

\section{$1.5 \quad$ Research Objective}

There is no single consensus on the most appropriate method to develop suitable materials for laser sintering and it is clear that no single property will provide an overall characterisation; however there are some core material characteristics that have been identified as key for successful laser sintering [10]. This paper will outline a targeted methodology and implementation protocol for developing new materials, exemplified by a new thermoplastic elastomer not previously used for laser sintering. To achieve this, a direct comparison of key laser sintering attributes will be made against PA12 and an additional commercially available elastomer material.

\section{$2 \quad$ Material and Experimental Procedures}

\subsection{Material Selection}

In this work three different materials were tested. PA12 (trade name PA2200 from EOS) was used as a benchmark material to guide the material selection and validation procedures for a new elastomer material that could expand the range of applications for the LS process. PA12 is a semi-crystalline polymer that has a wide super-cooling region which is a key factor for effective laser sintering [13]. A second 
material, ALM TPE-210s was selected because it is a commercially available laser sintering elastomer material. However, parts resulting from this material produce only a narrow range of mechanical properties. The third and final material that was selected was a powdered grade of an Elastollan thermoplastic polyurethane (TPU) supplied by BASF Gmbh (Table 1). An injection moulding grade of this material is currently used in the Burton product line for more flexible parts. Therefore, a low viscosity powdered grade of the material was selected according to its thermal and viscosity characteristics, using some of the selection criteria defined in Section 1 (above), that suggested its compatibility with the laser sintering process operated using conventional process design parameters.

Each of these materials was subjected to three different characterisation techniques including differential scanning calorimetry (DSC), hot stage microscopy (HSM), and particle size analysis. The characterisation tests validated the hypothesis that the TPU material possessed characteristics consistent with the requirements for the laser sintering process. (Subsequent tests using an EOS P100 laser sintering unit to create TPU tensile test specimens are outlined in Section 4.1).

\section{Table 1}

\subsection{Material characterisation methods}

\subsubsection{Differential Scanning Calorimetry}

This thermal measurement technique tracks changes in heat flow during primary phase transitions and is a commonly used technique to characterise polymer laser sintering materials. A TA Instruments Q200 (Figure 5) was used to perform the thermal analysis on the PA-12 and TPU samples. The ASTM D3418-08 protocol was followed for heating and sample preparation. Two separate samples of mass $6.6 \pm 0.1 \mathrm{mg}$ from the virgin batch of material were sealed inside an aluminium container and heated from 20- 
$220^{\circ} \mathrm{C}$ at $10^{\circ} \mathrm{Cmin}^{-1}$; nitrogen gas was used as a coolant at a flow rate of $50 \mathrm{~cm}^{3} \mathrm{~min}^{-1}$. Results were analysed using TA Universal Analysis Software.

\section{Figure 5}

\subsubsection{Hot Stage Microscopy}

Hot stage microscopy (HSM) was used as a practical measurement of the coalescence of the TPU powder particles. A Leica light microscope (Figure 6) with a dynamic heating rate program between $40^{\circ} \mathrm{C}-220^{\circ} \mathrm{C}$ at $10^{\circ} \mathrm{Cmin}^{-1}$ was used to observe the behaviour of a thin layer of polymer particles on a glass slide. These were recorded as video files, and repeated several times for each sample. The video was analysed using a software package (Image Pro Analyzer) by slicing the video into individual still images.

\section{Figure 6}

\subsubsection{Particle Size Analysis}

Particle size can play a significant role in the ability of a powdered material of high specific surface area to absorb heat and to flow. Larger particles require more heat and therefore can make sintering more challenging if significant amounts of energy are required to fully melt particles. Larger particles that do not fully melt can lead to porosity and a decrease in mechanical properties in sintered parts. The average particle size data for PA-12 $(56 \mu \mathrm{m})$ and ALM TPE-210s $(75-85 \mu \mathrm{m})$ were taken directly from the manufacturer's data sheets.

For the TPU material a small sample of powder was spread over a glass slide and then analysed under a microscope. Between 150-300 particle measurements were taken for each sample. The diameter of each particle was measured using imaging software called Image Pro-Plus. The elastomer powder is thought to have been 
manufactured by cryogenic grinding of pellets; this process often leads to jagged, irregular and non-spherical particles.

\section{$3 \quad$ Experimental Results}

\section{$3.1 \quad D S C$}

The DSC results for PA-12 and the elastomers are shown in Figures 7-9. The PA-12 thermogram shows a typical semi-crystalline plot with two distinct peaks describing the melting and re-crystallisation phase changes. A wide supercooling region, the temperature difference between the endothermic peak and the onset of the exothermic crystallisation peak is known to be desirable for polymers in the laser sintering process. From Figure 7, the measured supercooling range, when contrasting the melting endotherm for PA-12 powders and the subsequent cooling characteristics, is around $38{ }^{\circ} \mathrm{C}$ (if measured between peak temperatures), or $13{ }^{\circ} \mathrm{C}$ if determined between the onset temperatures of the respective transitions. It is also interesting to note the difference in the respective heat of fusion $\left(\Delta \mathrm{H}_{\mathrm{f}}\right)$ data, between the heating and cooling phases (Figure 7). Using a value of $209.3 \mathrm{Jg}^{-1}$ for a theoretical, $100 \%$ crystalline PA-12 sample [17], the crystallinity in the as-supplied powder (reflecting its thermal history) is around $46 \%$, compared to $21 \%$ crystallinity on cooling from the melt-state. This is consistent with DSC data published earlier [18]. The high melting temperature of $\gamma$ crystal form PA-12 $\left(185^{\circ} \mathrm{C}\right)$, together with the relatively high initial powder crystallinity, often results in double (and overlapping) endothermic peaks when laser sintered samples are subsequently analysed by DSC, for which peak melting endotherm temperatures of around $178{ }^{\circ} \mathrm{C}$ are also observed. Previous work has developed this observation to propose a 'degree of particle melt' (DPM) parameter, to correlate process history to measured mechanical properties [19], [20]. 
The thermogram for Elastollan TPU shows clear, but smaller and less distinct peaks, indicating small-scale molecular order, attributed to the hard crystallised segments in the thermoplastic elastomer. These broad but shallow endothermic and exothermic peaks indicate imperfect crystalline order, and are evident around $130^{\circ} \mathrm{C}$ (heating) and at $92^{\circ} \mathrm{C}$ (peak exothermic temperature on cooling). Thermal transitions are therefore much more defined in the Elastollan TPU (Figure 9), than in the ALM TPE-210s, which also exhibits evidence suggesting phase changes at low temperatures. The manufacturer's data sheet for this powder indicates a melting point of $178^{\circ} \mathrm{C}$ (tested according to ASTM D3418), however Figure 8 does not shows a clear phase change in this region in the DSC scan. A very shallow endotherm is visible in the same region as Elastollan but TPE-210s requires a much lower bed temperature $\left(\sim 70^{\circ} \mathrm{C}\right)$ for successful sintering.

The DSC data suggest that the Elastollan material has potential for successful sintering because of the existence of the crystalline order and the relatively wide processing window, around $37^{\circ} \mathrm{C}$, as determined by peak endothermic / exothermic transition temperatures. In turn, this suggests that the bed temperatures using on the sintering machine could approach the melting endotherm temperature without significantly impeding the flow of the material; the DSC data indicates that the bed temperature should be set in the region of $90-110^{\circ} \mathrm{C}$. Using an enthalpy value of 196.8 $\mathrm{Jg}^{-1}$ for $100 \%$ crystalline polyurethane segments ([21], the crystallinity data determined for TPU from Figure 9 are $8.6 \%$ (heating) and 7.4\% (cooling).

\section{Figures 7, 8,9}

\subsection{Hot Stage Microscopy}

The aims of the hot stage microscopy experiments were to identify differences in polymer sintering rates between the PA12, ALM TPE-210s, and Elastollan TPU and 
to verify the precise temperature range for melt-state sintering. Earlier published work has reported on a wider range of laser sintering materials including other polyamides and elastomers [10]. The still images in Figures 10-12 were used to visualise particle coalescence and to calculate the ratio of neck growth to produce particle radius versus time data, using Equation 1.

\section{Figures 10, 11, 12}

In practical HSM it is difficult to find two particles that are exactly the same equivalent diameter, made more complex by the irregular particle shapes; therefore the average of the two sintering particles was used to calculate the (y/a) ratio along with the growing neck diameter (y), as is visually illustrated in Figure 13. In simple viscous models such as Equation 1, particle coalescence is related to the ratio of physical parameters: surface free energy and viscosity. Whilst changes in surface free energy are relatively small for the same polymer type, viscosity can vary by orders of magnitude with molar mass, so that low molecular weight / low viscosity materials of the same polymer type are therefore expected to sinter faster than high viscosity / high molar mass grades. It is thought that faster coalescence will lead to optimised sintering behaviour because it would raise the probability of creating more fully dense parts, during the subsequent slow-cooling phase of the laser sintering process.

The DSC traces of PA-12 suggest more effective sintering than the Elastollan material due to the sharp thermal transitions and wide supercooling range. This was reflected in the actual calculation of sintering rate between the two materials, derived from the HSM data above, which is summarised in Figure 14. The experimental data show clear distinctions between the three polymers studied. A full rheological characterisation would be required in order to fully interpret the sintering data in Figure 14; this has already been completed for PA-12, highlighting the strong dependence of 
sintering kinetics on the zero-shear viscosity parameter and its dependence on molecular weight [22].

\section{Figures $13 \& 14$}

\subsection{Particle Size Distribution}

Figure 15 shows the particle size distribution for an unused sample of the Elastollan powder. The mean particle size was around $58 \mu \mathrm{m}$ with a standard deviation of $22 \mu \mathrm{m}$; this result confirms that the particle size distribution is very close to the PA12 commercial material, suggesting that differences in particle size are unlikely to contribute significantly to the observed differences in sintering behaviour.

\section{Figure 15}

The analytical research output presented in Section 3 was determined in an exploratory capacity, in order to provide information upon which to design an appropriate range of process conditions for the TPU elastomer in the P-100 laser sintering unit - see Section 4.

\section{$4 \quad$ Results and Discussion - Laser Sintering}

The results of the material characterisation described in Section 3 provided confidence to progress to initiate practical investigations on commercial laser sintering equipment. The following sections describe the methodology for these investigations and the initial evaluation of mechanical properties using tensile test results.

\subsection{LS parameters}

In order to assess not only the sintering behaviour of the TPU material, but also the mechanical properties which could be achieved on sintered parts, tensile test specimens were produced on an EOS Formiga P100 Laser Sintering system. Specimens were produced in the $\mathrm{YX}^{*}$ direction and according to British Standard BS EN ISO 527- 
2:1996, in virgin (un-used) material. (* Note - the bed of the machine is in the X-Y plane, with the $\mathrm{x}$-axis corresponding to the front of the machine).

\subsubsection{Part bed temperature}

A factor crucial to the success of laser sintering is the ability to deposit the powder bed smoothly at the temperature at which the build is to be conducted. Initial tests were performed to deposit several layers of powder at increasing part bed temperatures, and a temperature of $95^{\circ} \mathrm{C}$ was reached before any decrease in deposition quality was observed. This temperature was therefore selected as the build temperature for these experiments with TPU. This provides practical verification of the inference from the DSC data in Figure 9, since $95{ }^{\circ} \mathrm{C}$ coincides with the temperature range immediately before the onset of the shallow melting endotherm.

\subsubsection{Laser process parameters}

In order to provide an indication of the operating window within which parts could be sintered successfully, a range of energy input was provided through varying the laser power $(\mathrm{P})$ parameter setting for the process. In order to gain some understanding of the effects of processing speed, a second set of specimens was produced, whereby the laser power was held constant, and the energy input varied by changing the laser scan speed $\left(\mathrm{v}_{\mathrm{b}}\right)$. These settings were designed to ensure that the range of energy input from the laser corresponded with the range achieved using laser power variations. The correct settings were calculated using the Andrews number for energy density, the equation for which is shown in Equation 2 [23]:

$$
U_{A}=\frac{P}{V_{s} v_{b}}
$$


where $\mathrm{U}_{\mathrm{A}}$ is energy density, $\mathrm{P}=$ laser power, $\mathrm{v}_{\mathrm{b}}=$ beam speed (scan speed) and $\mathrm{V}_{\mathrm{s}}=$ slicer fill scan spacing (in consistent units).

This definition gives the energy density per unit area of sample (hence $\mathrm{U}_{\mathrm{A}}$, in $\mathrm{J} \mathrm{mm}^{-2}$ ). As recognised by Starr et al, an alternative parameter (volume energy density, $\mathrm{U}_{\mathrm{V}}$, in $\mathrm{J}$ $\mathrm{mm}^{-3}$ ) can also be used to quantify energy density input, in circumstances where layer thickness ( $\mathrm{z}$ ) is subject to change [24]; $\mathrm{U}_{\mathrm{V}}$ is defined as:

$U_{V}=\frac{P}{V_{S} v_{b} z}$

In our experiments, layer thickness (z) was constant, so that the area energy density $\left(\mathrm{U}_{\mathrm{A}}\right)$ has been used in the analysis. Three tensile test specimens were therefore produced under each of the 6 different conditions shown in Table 2.

Table 2

\subsection{Tensile testing}

Test specimens were conditioned at $20^{\circ} \mathrm{C}\left( \pm 1^{\circ} \mathrm{C}\right)$ and 50 percent $( \pm 5 \%)$ relative humidity prior to testing. A Zwick Z030 tensometer fitted with a long travel contact extensometer was used to perform the tests. Material modulus was measured using a $1 \mathrm{~mm} \mathrm{~min}^{-1}$ strain rate to $0.25 \%$ strain, following which the tensile strength and elongation at break were measured at $5 \mathrm{~mm} \mathrm{~min}^{-1}$ until specimen failure. The software provided by Zwick ('TestXpert'), was used for the calculation of the tensile strength, modulus, and elongation at break for each of the parts.

\subsection{Results and Discussion}

\subsubsection{Qualitative observations}

The experiments conducted here showed Elastollan TPU to be a highly processable material by conventional laser sintering. Initial attempts at building parts in practice 
were met with success, and no apparent difficulties were observed in terms of powder deposition, powder flow or sintering behaviour.

\subsubsection{Tensile Strength}

The tensile strength parameter is an appropriate measurement and Figure 16 demonstrates the effect of energy density on the tensile strength of the parts produced.

\section{Figure 16}

It can be seen that as energy density was increased, the tensile strength of the parts produced also increases, in a linear fashion. Increasing from the low to the high value of energy density leads to more than double the tensile strength (an average of 6.5MPa as opposed to $3 \mathrm{MPa}$ ). Crucially, the manner in which these different energy inputs were applied (varying the laser power or the scan speed) has no discernable effect on the overall trend observed. This result carries obvious advantages when laser processing more complex parts in future and is relevant to further developments in process design for the laser sintering of thermoplastic elastomers.

\subsubsection{Tensile Modulus data}

Figure 17 demonstrates the effect of energy density on the tensile modulus of the materials, determined from the parts produced by laser sintering.

\section{Figure 17}

Once again, a positive correlation can be observed, whereby an increase in energy density from the lowest to the highest level leads to an increase in average tensile modulus from 50.2 to $122.2 \mathrm{MPa}$. As is generally observed in laser sintered parts, the results for tensile modulus show much larger variations than for the tensile strength data. However, as previously shown, the results obtained by varying the selected process parameters (laser power or the scan speed) demonstrate no apparent difference in the overall qualitative relationships observed. 


\subsubsection{Elongation at Break}

Figure 18 shows the effect of energy density on the elongation at break measured on the laser sintered elastomer specimens.

\section{Figure 18}

Once again a linear positive trend was observed when increasing energy density, with an increase from $77.0 \%$ at the low level to $149 \%$ (almost double) at the higher level. The range of results at each energy density is slightly higher than for the tensile strength data, but substantially lower than for modulus. Again, this would be expected when considering commercial laser sintering materials.

\subsection{Discussion of Sintering Experiments}

Initial investigations with the TPU material have shown that successful sintering was possible, and that powder deposition was of a high quality, without requiring a more refined and controlled particle morphology, or the inclusion of further flowenhancing additives. Whilst further work will be needed to fully characterise the material (e.g. viscosity, surface energy and surface finish / hardness of sintered parts), these results demonstrate the success of the approach taken to identify appropriate materials for the LS process.

As would be anticipated from existing literature [18], [24], [25] and based on trends observed for commercial laser sintering materials, an increase in energy density leads to an increase in each of the three tensile properties tested, with modulus data demonstrating the largest spread of results at each energy density value. Crucially, increasing the energy input over the range of energy densities tested led to at least doubling each of the properties tested, with no observable effect on the ease or quality of practical sintering. Further optimisation may also be possible. This large processing window will provide benefits by allowing users to select from a range of properties, and 
may even offer the possibility to include a large range of properties within a single part or component. To-date, no attempts have been made to fully explore the extent of the process window (or the stable sintering region, [10]) by varying additional process parameters such as scan spacing or powder layer thickness. It is known that thermal history and composition of TPU can influence crystallisation behaviour and subsequent physical properties [26] and in addition, thermal degradation is reported to be likely at melt-state processing temperatures [27], [28].

As mentioned in section 4.3, varying the energy density was the major contributor to the changes in tensile properties and this was independent of the method by which this was achieved (ie. by changing laser power or scan speed). This implies that within the range of parameters studied, the material is not significantly affected by time-related issues within the process, or by the temperature variations induced in parts whilst waiting for completion of the sintering of other parts in a layer. This would be likely to improve the ability to process parts of large or differing cross-sections.

Standard practice with laser sintered elastomers is to use some form of postbuild infiltration to improve the properties of the parts produced. In the case presented here, relatively high properties were achieved at high energy density values, without the need for an additional infiltration step. This has implications both in terms of reducing the overall production time for part production, or offers the possibility that substantially higher properties may be achieved if infiltration were to be assessed.

A short assessment of the ability to recycle the post-build powdered material was also carried out on the TPU, and this showed no significant increase in difficulty of sintering, or decrease in part properties, over the course of three levels of recycling [29].

Overall, the investigations referred to here are thought to be the first reported for laser sintering of commercially available TPU powders; once the process was optimised 
using energy density criteria, the mechanical properties were generally higher than the current laser sintering elastomers commercially available.

\subsection{Overall Implications of the Research}

The three characterisation tests alone are not comprehensive tools for identifying a material's ability to be used in a conventional laser sintering process. Process modelling requires additional physical properties such as surface free energy (ideally reflecting the temperature-sensitivity in the region around the melting endotherm) and viscoelastic deformation / flow data appropriate to the process. However, the combination of insight from understanding the thermal properties, sintering characteristics, and particle size provide a more complete indication of whether the TPU material, an important example of the thermoplastic elastomer family, has suitable properties for commercial exploitation in laser sintering. An additional advantage is that the amount of powder required for thermal characterisation is minimal (less than $100 \mathrm{~g})$. A tabular summary of the results from the characterisation analysis is shown in Table 3.

\section{Table 3}

PA-12 was used as a baseline material because its effectiveness for the laser sintering process has been validated by a great deal of practical knowledge and experience. Additionally ALM TPE-210 was studied to evaluate the thermoplastic polyurethane material in comparison with an existing, commercially available laser sintering elastomeric material. Comparing the thermal characteristics measured by DSC indicated that the Elastollan material has a distinct process window between the endothermic / exothermic regions, although this is less clear than the more highlycrystalline PA-12. When processing PA-12 the bed temperature is typically set about $15^{\circ} \mathrm{C}$ below the onset of the melting endotherm; for Elastollan TPU, the material was 
processed using a bed temperature of $95^{\circ} \mathrm{C}$, again below the onset of melting of the imperfect crystallites, but about $35^{\circ} \mathrm{C}$ below the endothermic peak melting temperature. There were no indications of effects due to non-uniform cooling (such as distortion, curling) or other difficulties during the laser sintering process. Indications from the DSC curves, based upon the relatively wide but shallow nature of the melting endotherm, suggest that it may be possible to raise the bed temperature even higher, demonstrating some degree of flexibility in specifying optimum process settings and conditions.

More generally, it has been shown that a thermal characterisation using DSC and HSM allows an initial evaluation of the suitability of new materials for the laser sintering process. Further analysis, for example by thermogravimetric analysis (TGA) can be used to define a stable sintering region for existing and new laser sintering materials [10]. Sintering kinetics are then determined by the viscous properties of polymers in the region just above the melting endotherm [14] which are clearly strongly dependent on the molecular characteristics of a given polymer type, including the effects of any chemical changes on molecular architecture which may occur during the laser sintering process. The current investigations have demonstrated that individual process parameters can be adjusted towards an optimum level of energy density to yield acceptable mechanical properties, despite the large temperature differences that are likely to exist in different areas of the part bed.

The laser sintered parts that were processed gave impressive properties that were indicative of conventional elastomer materials and showed promise for industrial applications where high elongation, indicating durability and strain energy absorption, is required. This research therefore highlights some combinations of characterisation techniques which will enable more rapid synthesis and development of polymers 
suitable for laser sintering, contributing to the on-going expansion of the range of products and polymers being used for prototyping and in real manufacturing applications, to fully exploit the design freedom offered by laser sintering techniques.

\section{Conclusions}

Increasing numbers of industries are starting to adopt laser sintering technologies; however one of the major limitations of the process is the lack of material choice. The methods and conclusions of this work provide a systematic way to analyse and select potential candidates for use in the laser sintering process. In our approach, there was no focus on the individual constituents of the polymer grades; rather, a combination of characterisation techniques was adopted, to compare the known traits of the commercial laser sintering materials (PA-12 and ALM TPE-210s) with a TPU polymer not previously used in laser sintering.

Thermal characterisation by DSC allows specification of optimum process conditions and particle sintering kinetics can be studied in predictive mode using hotstage microscopy. Further characterisation using TGA would help to define the overall stable sintering region for new polymers and viscoelastic models are under development to predict sintering rates based upon fundamental material properties. Our results have demonstrated the importance of optimising a quantitative energy density parameter when laser sintering polymers, irrespective of the specific process settings changed to obtain variations in this parameter.

Future work would include the application of this method to additional polymer materials, especially helpful in end use applications for companies seeking a certain class of materials (or material property combinations, including composites and polyblends) that are not currently commercially available. This would streamline new materials development processes, as illustrated by the selection of Elastollan TPU in the 
current study. However, more research is required to develop simulative process models, identify optimum processing ranges, recyclability of powders and applicationspecific mechanical properties.

\section{$7 \quad$ Acknowledgements}

The authors would like to acknowledge the Engineering and Physical Sciences Research Council (EPSRC) of Great Britain and IMCRC at Loughborough University, as the primary funding source for this research. The work would not have been possible without the invaluable collaboration between our project partners: Burton Snowboards (USA), EOS Gmbh (Germany), and the University of Louisville (USA).

\section{$8 \quad$ References}

[1] Hopkinson, N., Hague, R.J.M., Dickens, P.M. (Eds.). (2005) "Rapid Manufacturing and Industrial Revolution for the Digital Age”, Chichester: John Wiley and Sons Ltd ISBN 0-470-01613-8.

[2] Wohlers Report (2013). Additive manufacturing and 3D Printing Annual Worldwide Progress report., Wohlers Associates, ISBN 0-9754429-9-6. .

[3] Bellehumeur, C.T., Bisaria, M.K., Vlachopoulos, J. (1996) “An Experimental Study and Model of Polymer Sintering”. Polymer Engineering and Science 36, (17) pp. 21982207.

[4] Goodridge, R., Tuck, C., Hague, R. (2011) "Laser sintering of polyamides and other polymers". Progress in Materials Science. 57, (2), pp 229-267.

[5] Hardro, P., Wang, J. \& Stucker, B. (1999), "Determining the parameter settings and capability of a rapid prototyping process", International Journal of Industrial Engineering, 6, (3), pp. 203-213. 
[6] Shi, Y., Chen, J., Wang, Y., Li, Z. Huang, S. (2007) "Study of laser sintering of polycarbonate and post process for parts reinforcement". Journal of Applied Polymer Science 221, (1) pp. 37-42.

[7] Nelson, J., Vail, N., Barlow, J., Beaman, J., Marcus, H, Bourell, D. (1995) “Model of the Selective Laser Sintering of bisphenol-A polycarbonate", Ind. Eng. Chem. Res. 32 (10), 2305-2317.

[8] Goodridge, R., Hague, R., Tuck, C. (2009) “An empirical study into laser sintering of UHMWPE”. Journal of Materials Processing Technology 210, (1) pp 72-80.

[9] Schmidt, M., Pohle, D., Rechtenwald, T. (2007), "Selective Laser Sintering of PEEK", Annals of the CIRP, 56, (1), pp. 205-208.

[10] Vasquez, M., Haworth, B., Hopkinson, N. (2011) “Optimum sintering region for laser sintered nylon-12”, I. Mech. E. Part B: Journal of Engineering Manufacture 225 (17), pp. 2240-2248.

[11] Zarringhalam, H.. (2007) "Investigation into Crystallinity and Degree of Particle Melt in Selective Laser Sintering”. PhD Thesis, Loughborough University.

[12] Wohlers Report (2009). Additive manufacturing and 3D Printing Annual Worldwide Progress report., Wohlers Associates

[13] Dickens, E.; Lee, B., Taylor, G. Magistro, A., Hendra, N. McAlea, K., Forderhase, P. (1996) Sinterable semi-crystalline powder and near fully dense article formed therewith. United States Patent Number 5,527,877.

[14] Haworth, B. Hitt, D.J., Hopkinson, N., Vasquez, M. (2013) “Laser Sintering Process for Polymers: Influence of Molecular Weight and definition of a Stable Sintering Region", PPS-29 International Conf., Nuremberg, Germany, S18-308. [15] Bellehumeur, C.T., Kontopoulou, M., Vlachopoulos, J. (1998) "The role of viscoelasticity in polymer sintering", Rheol. Acta 37, pp. 270-278. 
[16] Evans, R.S., Bourell, D.L., Beamen J.J., Campbell, M.I. (2005) Selective Laser Sintering Materials Development Method for Rapid Manufacturing. 16th SFF Symposium. 184-19.

[17] Goglowski, S., Czerniawska, K., Gasiorek, M., (1980) "Effect of Annealing on Thermal Properties and Crystalline Structure of Polyamides, Nylon-12 (Polylaurolactam)”. Colloid \& Polymer Science, 258, (10), pp. 1130-1136.

[18] Majewski, C.E., Zarringhalam, H., Hopkinson, N. (2009) "Effects of Degree of Particle Melt and Crystallinity in SLS Nylon-12 Parts", $19^{\text {th }}$ Solid Freeform Fabrication Symposium, Austin, Texas, pp. 45-53.

[19] Majewski, C., Zarringhalam, H. Hopkinson, N. (2008), "Effect of the degree of particle melt on mechanical properties in selective laser-sintered nylon 12 parts", $I$. Mech. E. Part B - Journal of Engineering Manufacture, 222 (9) pp. 1055-1064.

[20] Hopkinson, N., Majewski, C.E., Zarringhalam, H. (2009) "Quantifying the Degree of Particle Melt in Selective Laser Sintering”, 58, pp. 197-200.

[21] Zhu, Y., Hu, J., Choi, K., Yeung, K., Meng, Q., Chen, S. (2008) “Crystallization and melting behaviour of the crystalline soft segment in a shape-memory polyurethane ionomer," Journal of Applied Polymer Science, 107, (1), pp. 599-609.

[22] Haworth, B., Hopkinson, N., Hitt, D.J., Zhong, X. (2013) “Shear viscosity measurements on Polyamide-12", Rapid Prototyping Journal, 19 (1), pp. 28-36. [23] Lu, L., Fu, J.Y.H. (2001) "Laser Induced Materials and Processes for Rapid Prototyping”, Kluwer Press.

[24] Starr, T.L., Gornet, T.J., Usher, J.S. (2011) “The effect of process conditions on mechanical properties of laser-sintered nylon”, Rapid Prototyping Journal, 17 (6), pp. 418-423. 
[25] Caulfield, B., McHugh, P. E., Lohfeld, S. (2007) “Dependence of mechanical properties of polyamide components on build parameters in the SLS process", J. Mater. Process. Tech., 182, pp. 477-488.

[26] Pistor, V., de Conto, D., Ornaghi, F.G., Zattera, A.J. (2012) "Microstructure and Crystallisation Kinetics of Polyurethane Thermoplastics Containing Trisilanol Isobutyl POSS", J. Nanomaterials, 2012, pp. 1-8.

[27] Hentschel, T., Munstedt, H. (2001) "Kinetics of the molar mass decrease in a polyurethane melt: a rheological study”, Polymer 42 (7), pp. 3195-3203. [28] Finnegan, B., Martin, D., Halley, R., Truss, R., Campbell, K. (2004) “Morphology and properties of thermoplastic polyurethane nanocomposites incorporating hydrophilic layered silicates". Polymer 45 (7), pp. 2249-2260.

[29] Plummer, K., Vasquez, M., Majewski, C., Hopkinson, N. (2012) "Study into the recyclability of a thermoplastic polyurethane powder for use in laser sintering," I Mech. E. Part B: Journal of Engineering Manufacture. 225 (17) pp.1127-1135. 


\section{9}

\section{Figures}

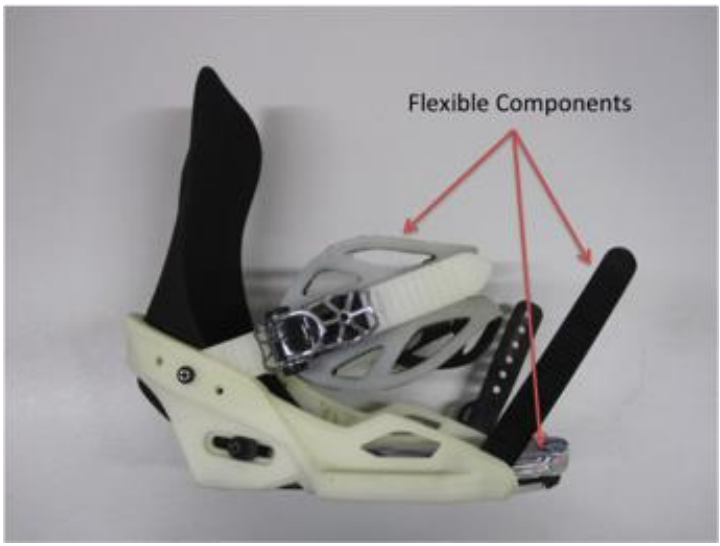

Figure 1: Burton Snowboards prototype binding with examples of flexible, elastomeric components 


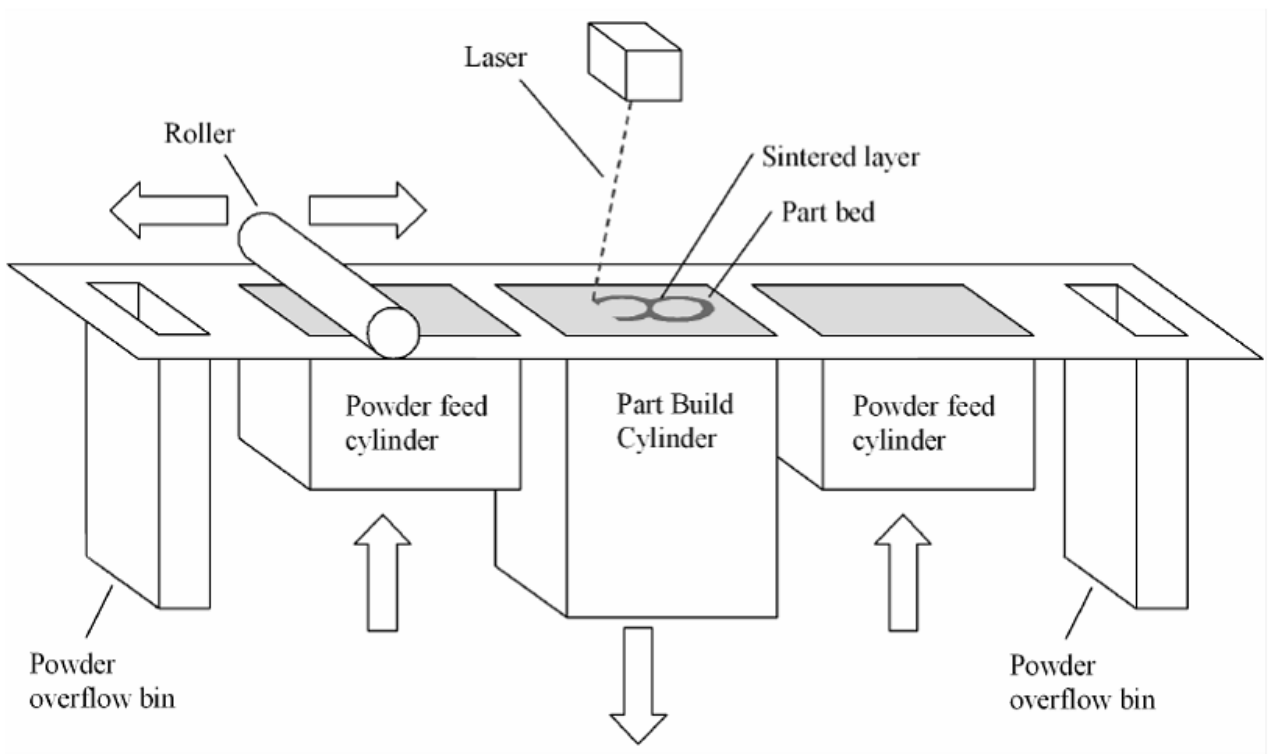

Figure 2: Typical laser sintering machine setup [11] 


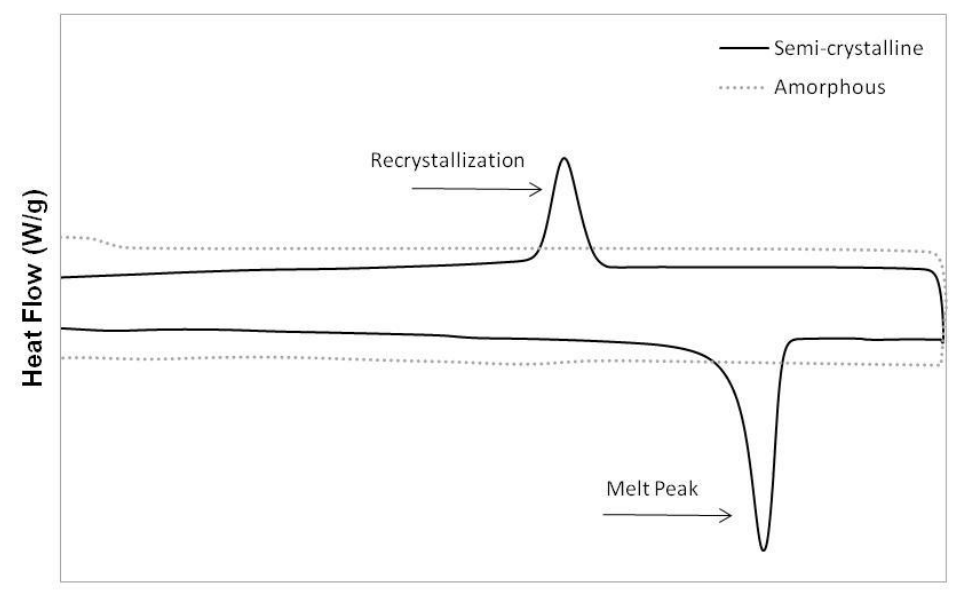

Temperature $\left({ }^{\circ} \mathrm{C}\right)$

Figure 3: Typical DSC traces for a semi-crystalline and an amorphous material 


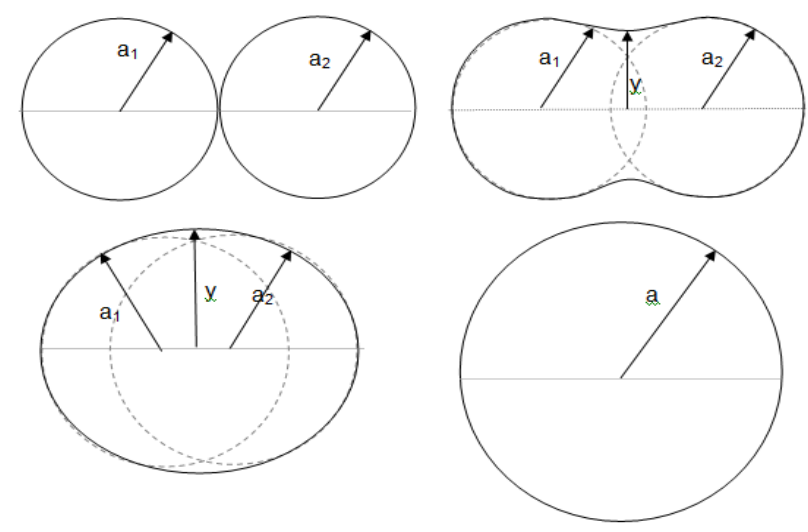

Figure 4: Illustration of polymer sintering according to Frenkel-Eshelby viscous model 


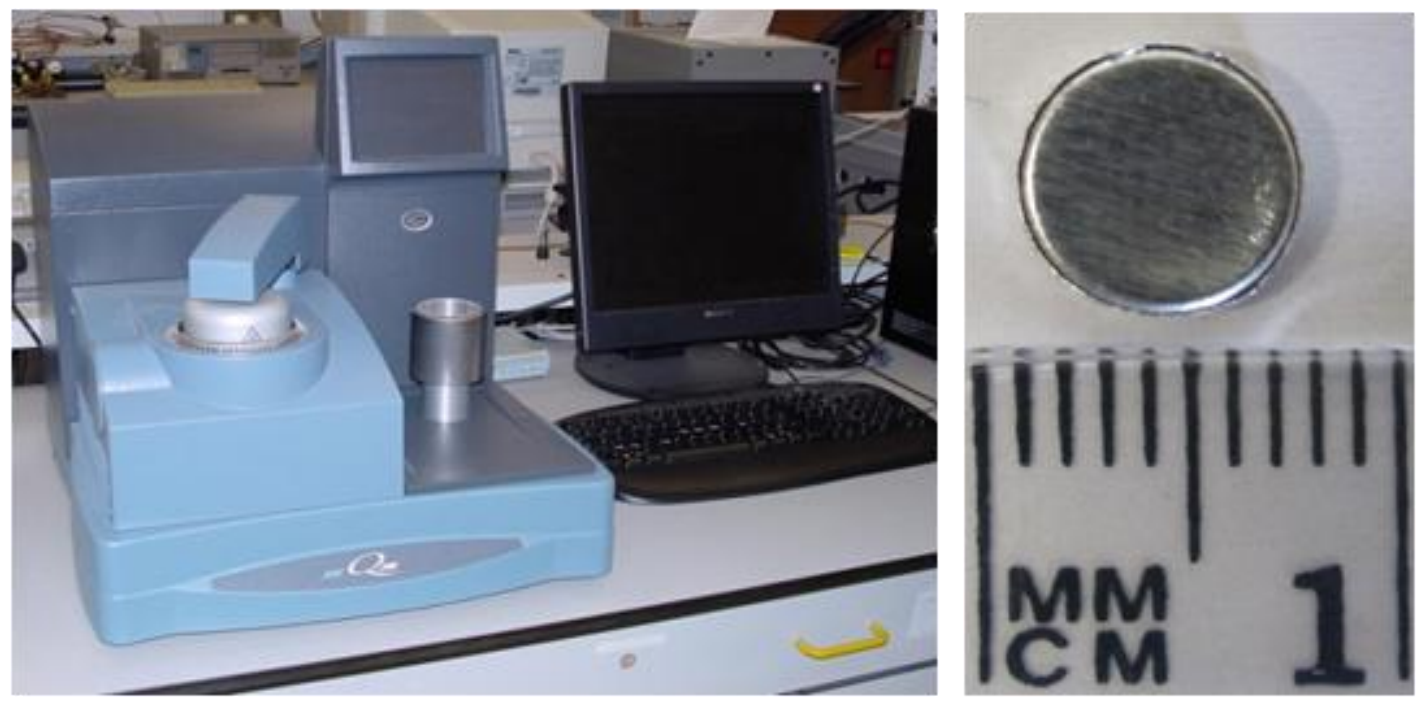

Figure 5: TA Instruments Q200 DSC with typical sample tray 

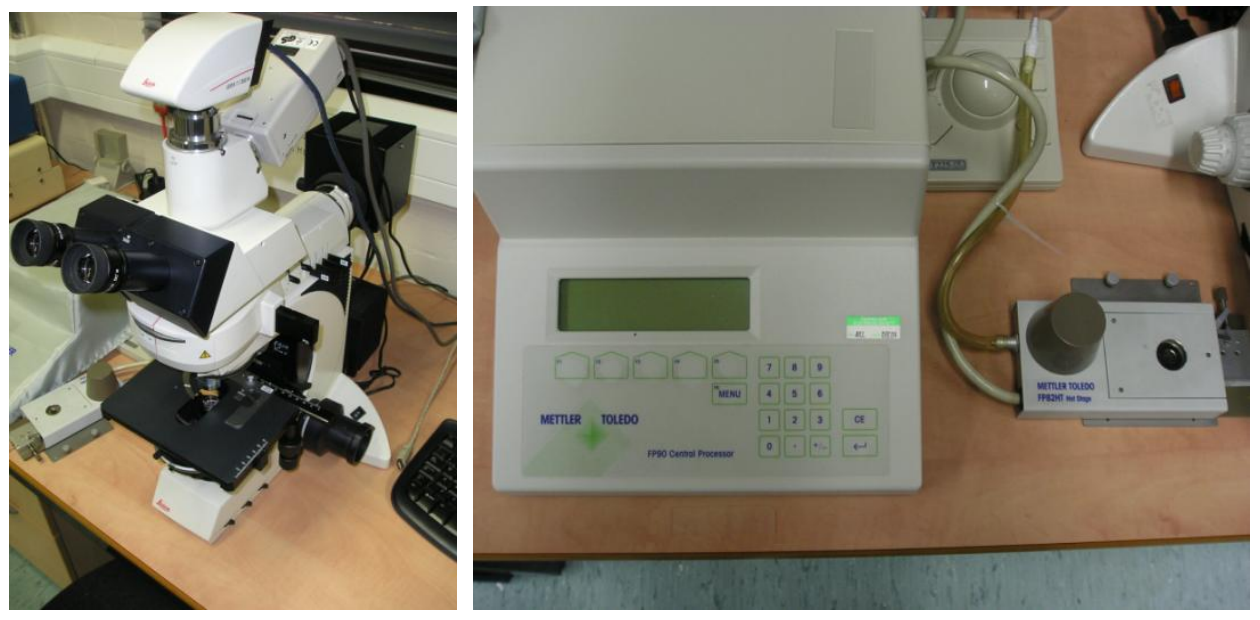

Figure 6: Leica light microscope with Mettler Toledo hot stage attachment 


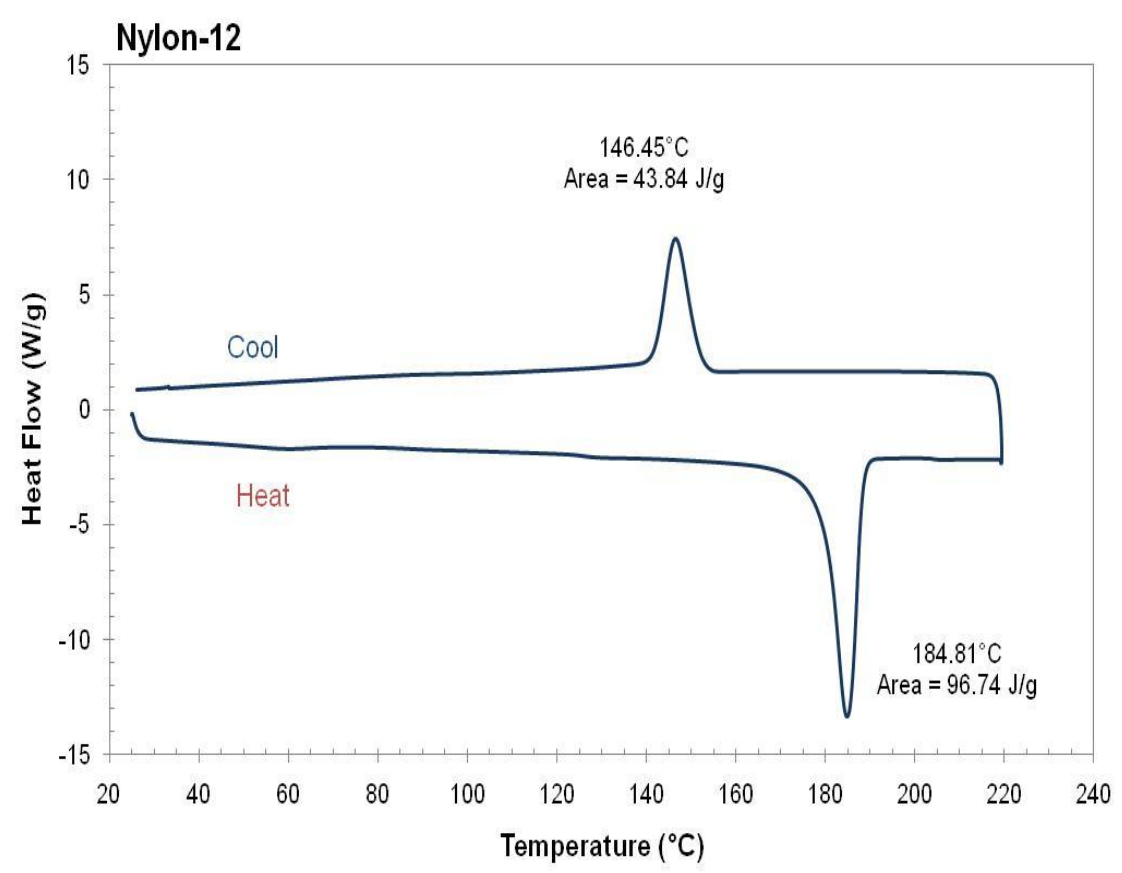

Figure 7: DSC thermogram for PA-12 powder 


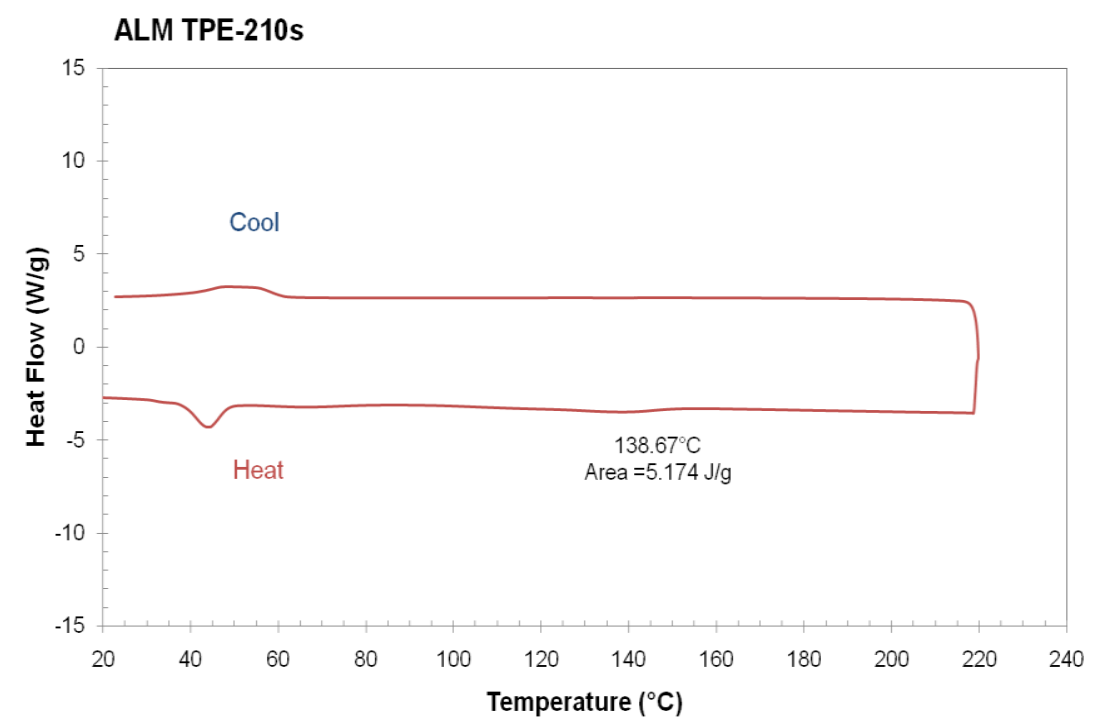

Figure 8: DSC thermogram for ALM TPE-210s powder 


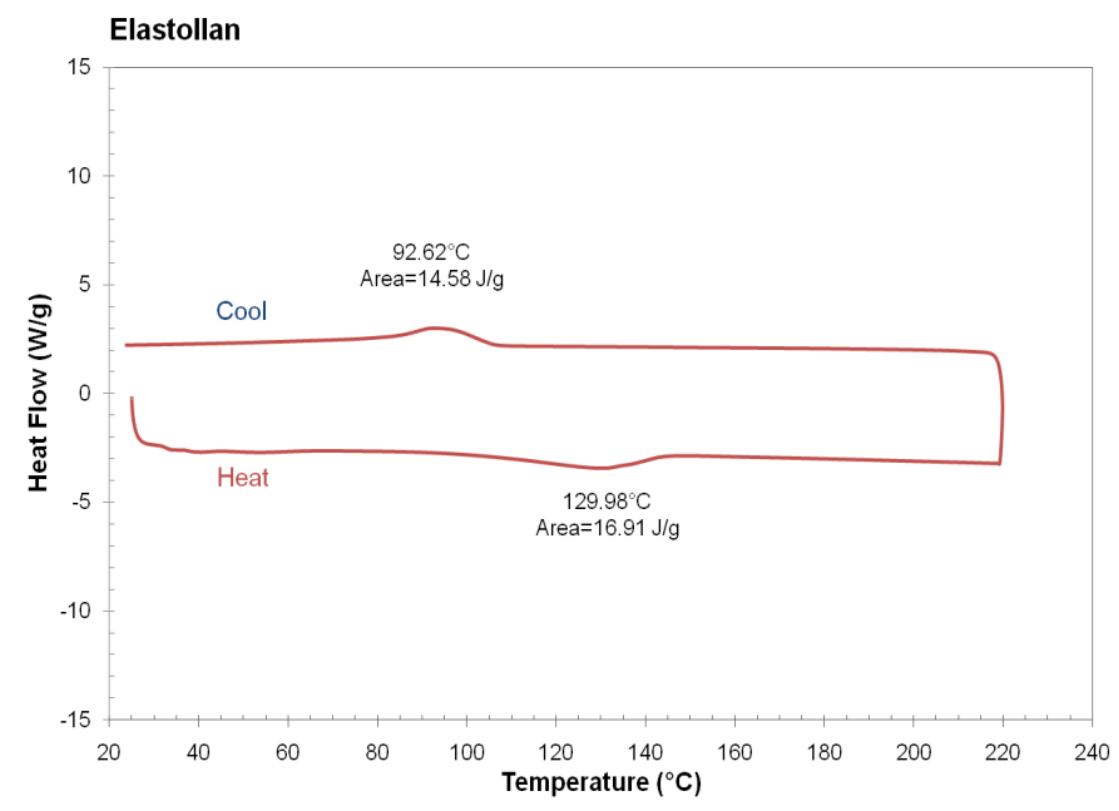

Figure 9: DSC thermogram for TPU powder 


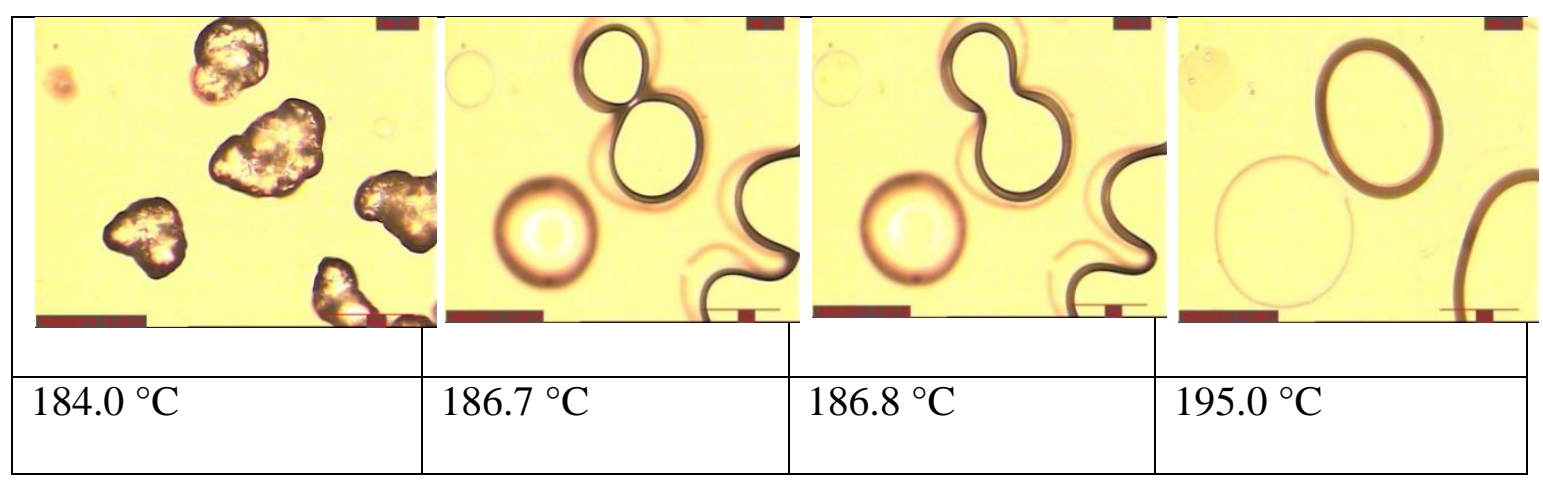

Figure 10: PA-12 hot stage microscopy (Scale bar $=50$ microns) 


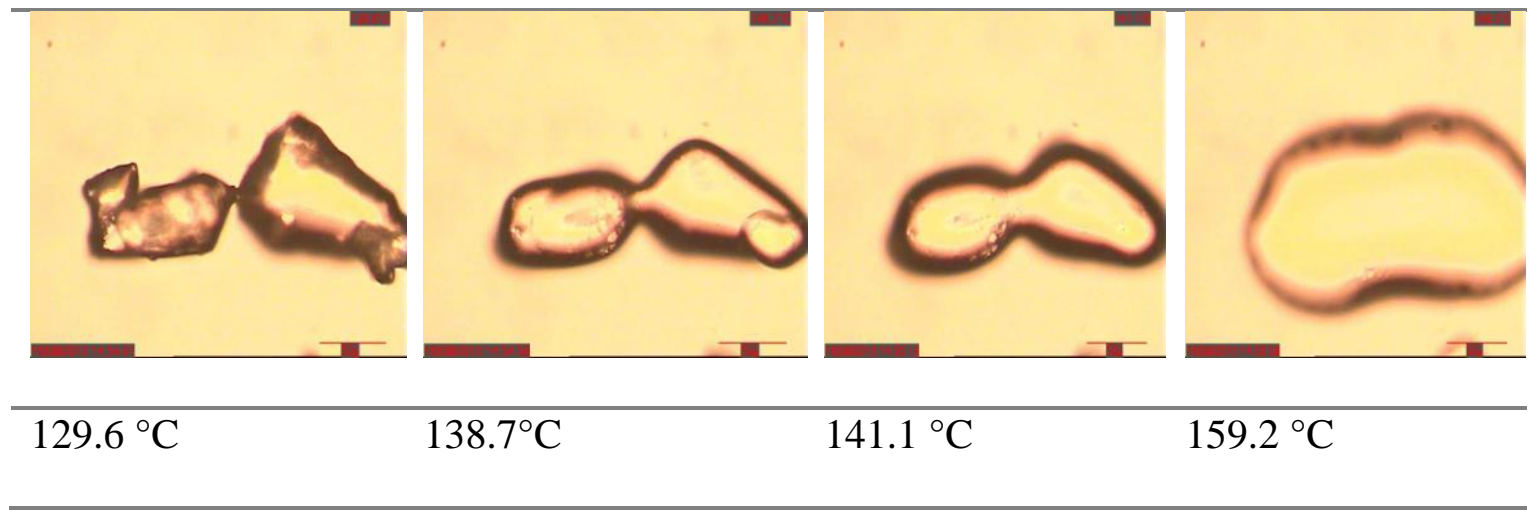

Figure 11 ALM TPE-210s hot stage microscopy (Scale bar $=50$ microns) 


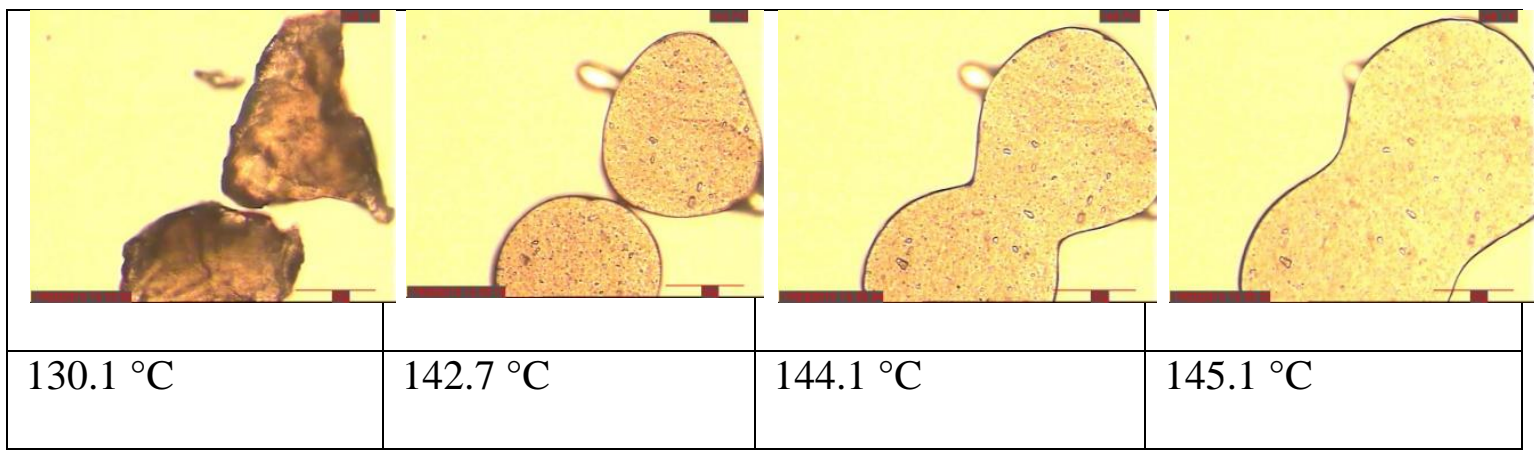

Figure 12: Elastollan TPU hot stage microscopy (Scale bar $=50$ microns) 


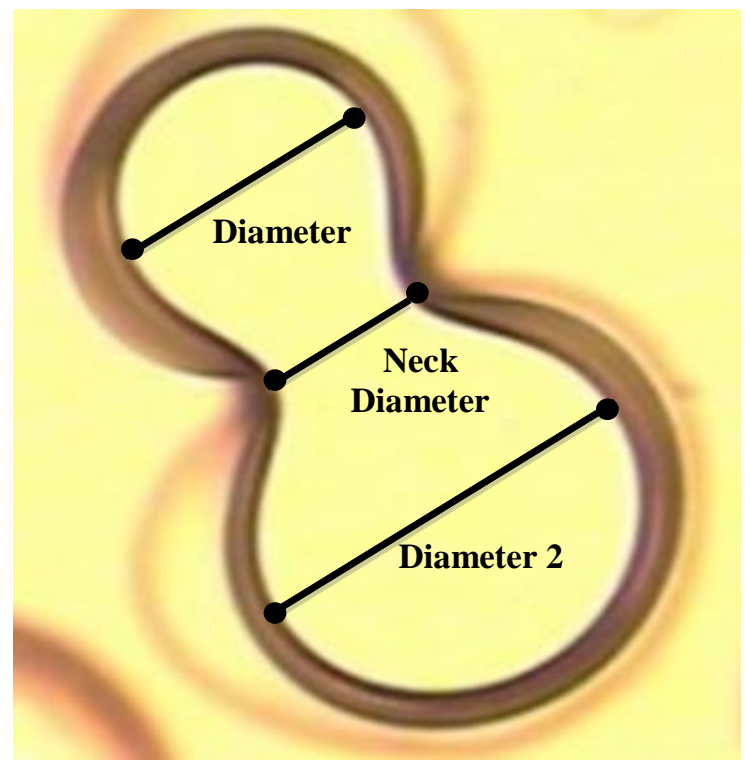

Figure 13: Dimensions used in the calculation of neck growth versus particle size 


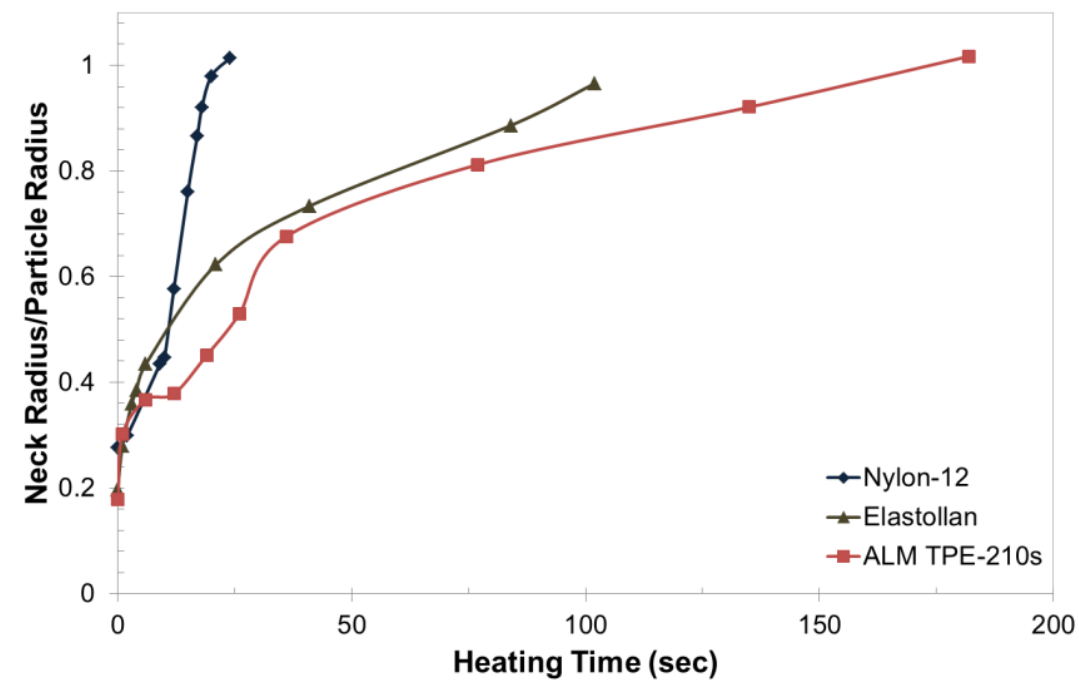

Figure 14: Polymer sintering rates, observed from practical hot-stage microscopy 


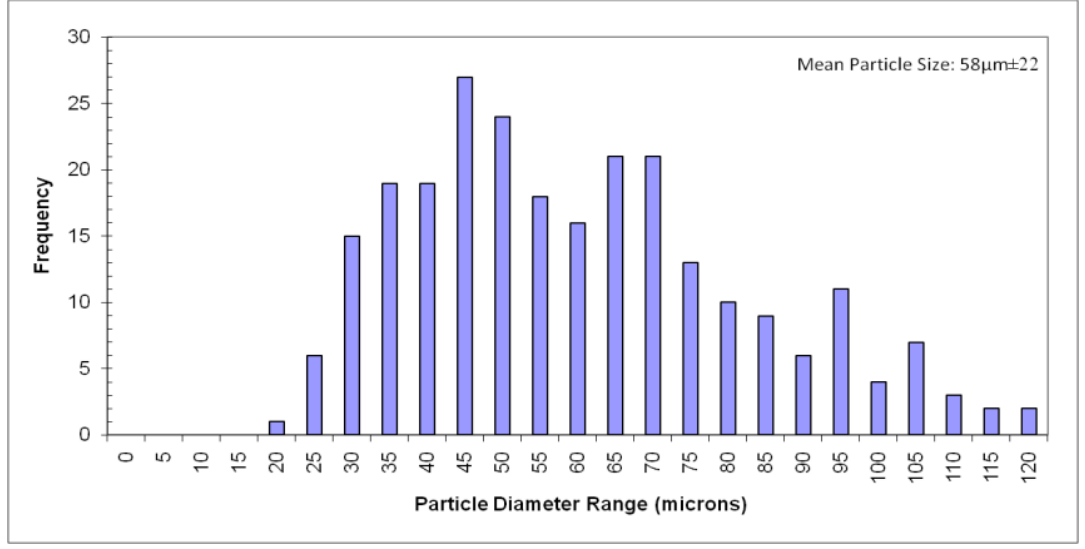

Figure 15: Particle Size Analysis for Elastollan powder 


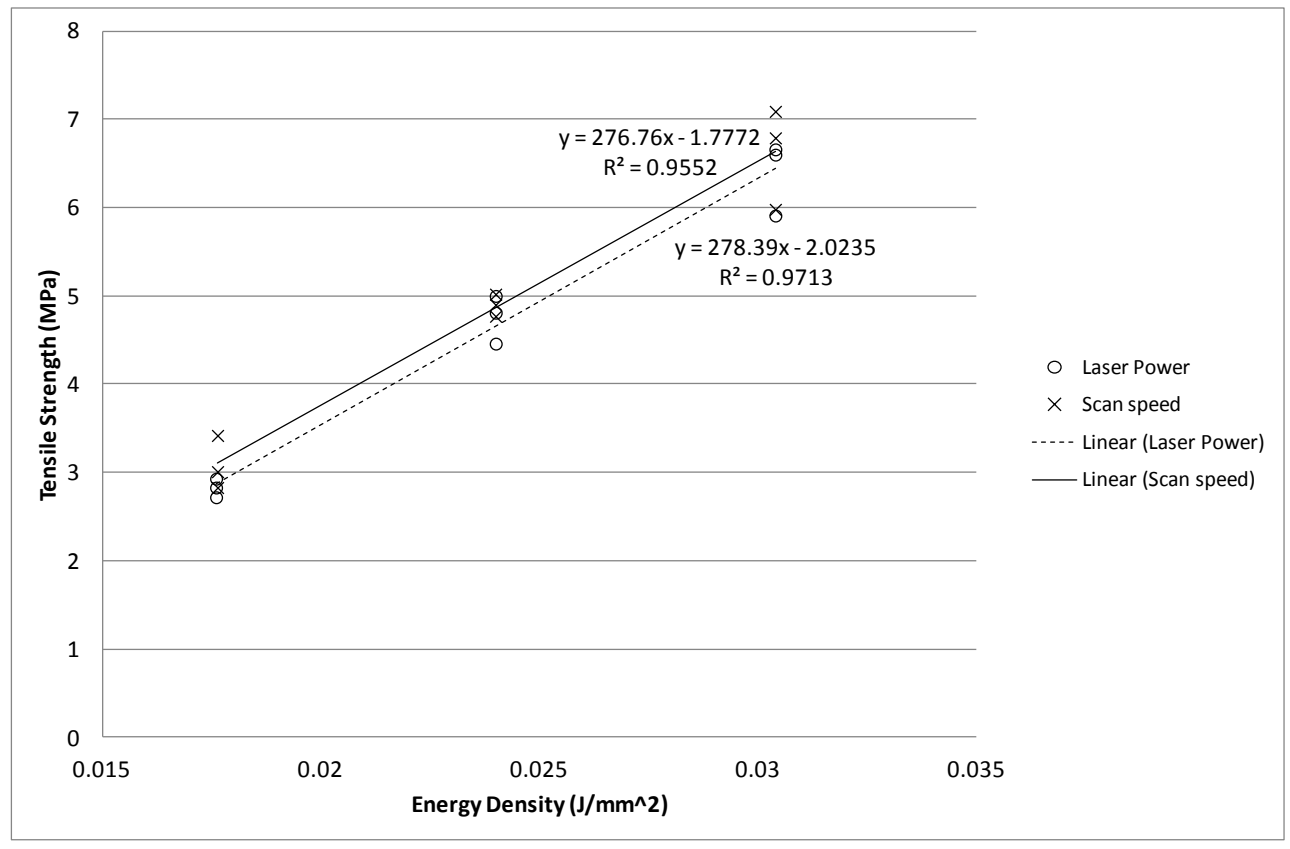

Figure 16: Effect of laser power and scan speed on tensile strength of laser-sintered TPU parts 


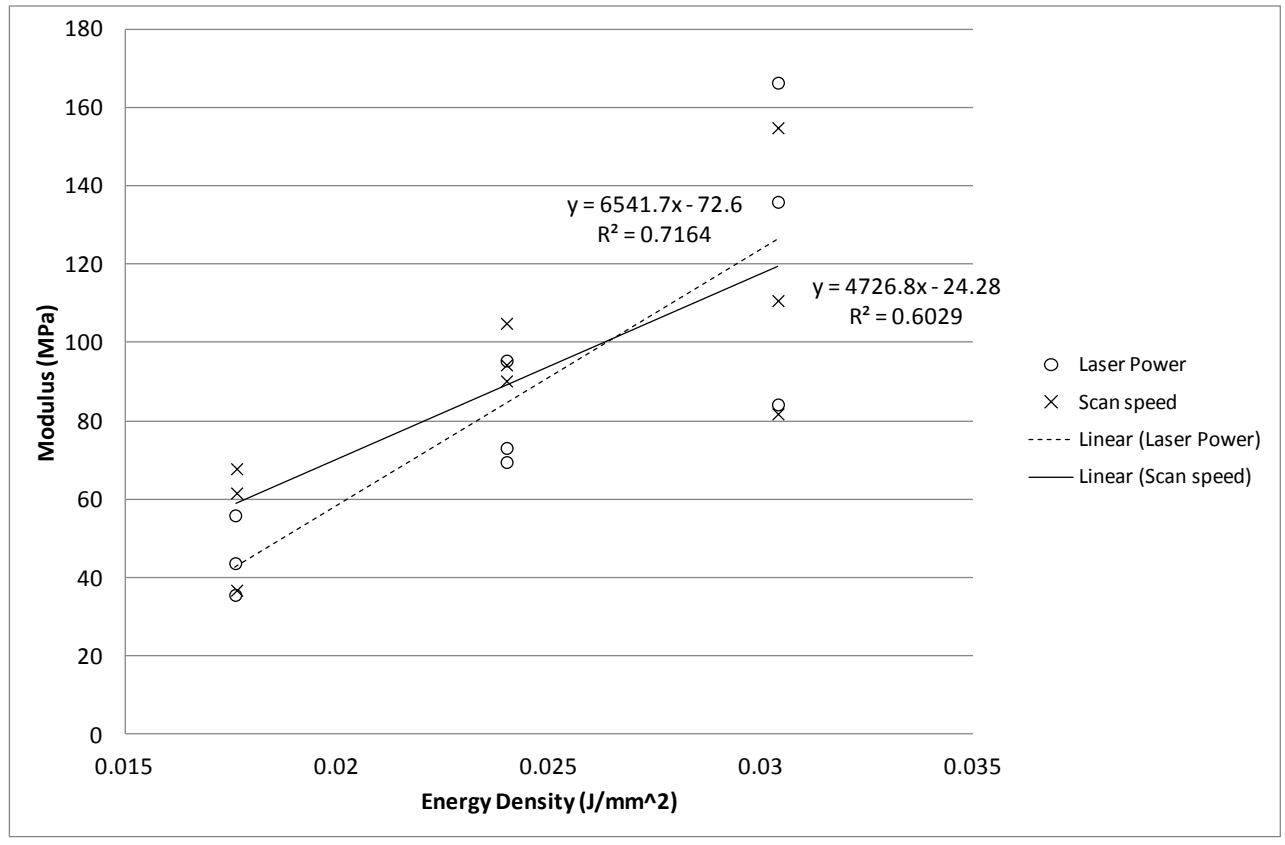

Figure 17: Effect of laser power and scan speed on tensile modulus of laser sintered TPU parts 


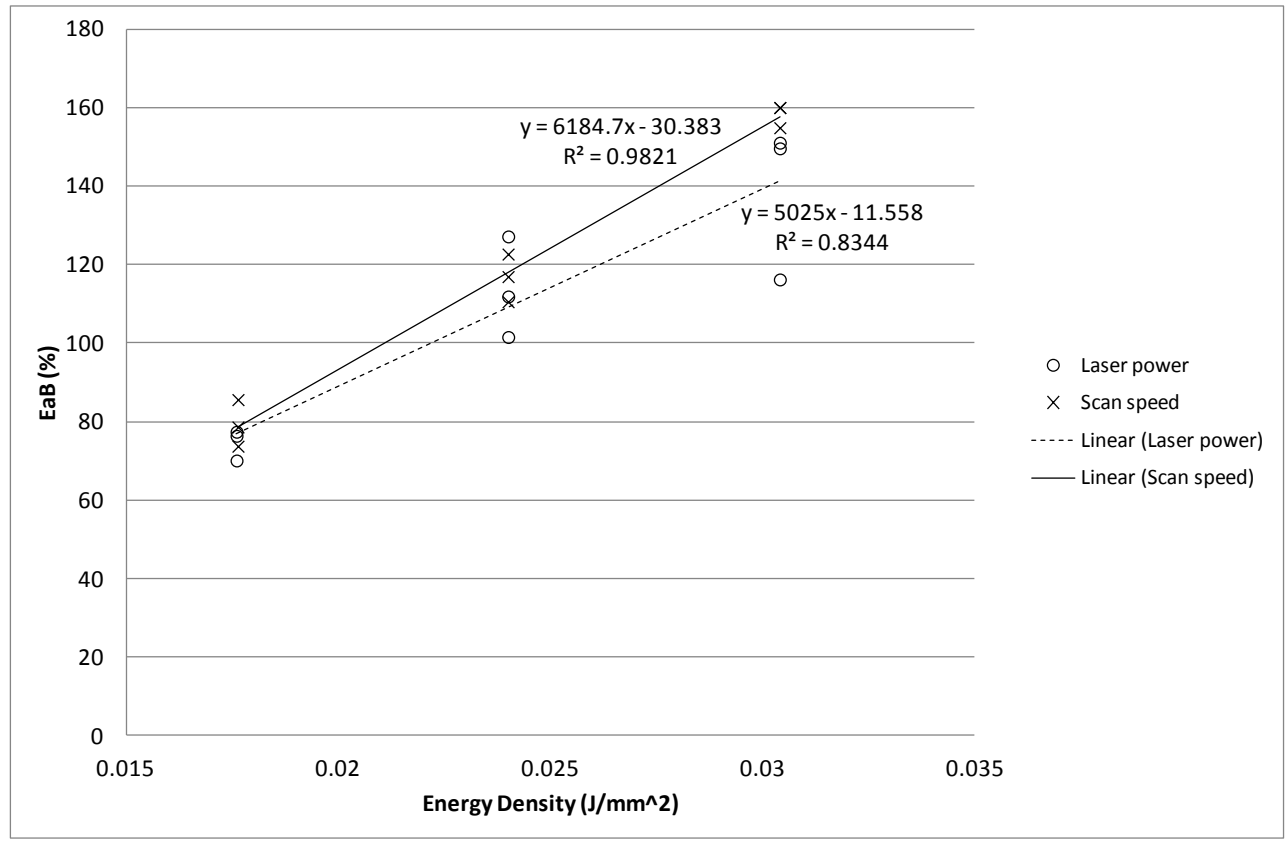

Figure 18: Effect of laser power and scan speed on elongation at break 
Tables

\begin{tabular}{|l|l|l|}
\hline Trade Name & Material Type & Description \\
\hline EOS PA2200 & Polyamide-12 & Standard laser sintering material used \\
& & primarily for rigid parts \\
\hline ALM TPE-210s & Thermoplastic & Commercially available laser sintering \\
& Elastomer & elastomer \\
\hline BASF Elastollan & Thermoplastic & Elastomer material grade available for \\
& Polyurethane & processes requiring a low viscosity. \\
\hline
\end{tabular}

Table 1: List of Materials and Grades 


\begin{tabular}{|l|l|}
\hline Build parameter & Setpoint \\
\hline Fill laser power (contours) & $8 \mathrm{~W}$ \\
\hline Fill laser power (hatching) - effect of laser power & $11,15,19 \mathrm{~W}$ \\
\hline Fill laser power (hatching) - effect of scan speed & $19 \mathrm{~W}$ \\
\hline Scan spacing & $0.25 \mathrm{~mm}^{-1}$ \\
\hline Scan speed (contours) & $1500 \mathrm{~mm} \mathrm{~s}^{-1}$ \\
\hline Scan speed (hatching) - effect of laser power & $2500 \mathrm{~mm} \mathrm{~s}^{-1}$ \\
\hline Scan speed (hatching) - effect of scan speed & $4310,3167,2500 \mathrm{~mm} \mathrm{~s}^{-1}$ \\
\hline Part bed temperature & $95{ }^{\circ} \mathrm{C}$ \\
\hline Layer thickness & $0.1 \mathrm{~mm}^{-1}$ \\
\hline
\end{tabular}

Table 2: Laser Sintering parameters for TPU powders 


\begin{tabular}{|l|l|l|l|l|}
\hline & DSC & HSM & & \\
Material & (Process window \& & (Coalescence & Particle Size & LS Part \\
& phase & Rate) & (Flow) & Properties \\
\hline Polyamide-12 & + & & + & + \\
\hline ALM TPE- & - & + & + & \\
210s & & - & + & + \\
\hline Elastollan & + & & + & \\
\hline TPU & & - & & + \\
\hline
\end{tabular}

Table 3: Summary of sintering characteristics for PA-12 and Elastollan TPU 